\title{
The Readiness of Peninsular Malaysia Wood-based Industries for Achieving Sustainability
}

\author{
Nur Amira Zainul Armir, ${ }^{a}$ Sarani Zakaria, ${ }^{a, *}$ Rawshan Ara Begum, ${ }^{\mathrm{b}}$ Norshamliza \\ Chamhuri, ${ }^{\mathrm{c}}$ Noratiqah Mohd Ariff, ${ }^{\mathrm{d}}$ Jalaluddin Harun, ${ }^{\mathrm{e}}$ Noor Laila Mohd Talib, \\ and Mohd Amin Kadir ${ }^{\mathrm{e}}$
}

\begin{abstract}
Forests represent a substantial part of global socio-economy platforms. As the wood-based industry contributes large revenue to Malaysia's economy, the readiness of Peninsular Malaysia towards sustainable wood-based industry was measured based on the different types of wood processing industries and Sustainable Forest Management (SFM) practice. Surveys $(1,447)$ from all operating timber mills according to their raw materials type for wood products processing in Peninsular Malaysia were analyzed using multiple correspondence analysis (MCA). Results showed that the sustainable practice in wood industry by SFM practitioners and non-practitioners were similar. All industries are using outdated technologies and consume local raw materials in producing wood products. The furniture industry is largely aware of SFM and consumes the least amount of logs to produce furniture.
\end{abstract}

Keywords: Peninsular Malaysia wood-based industry; Multiple Correspondence Analysis; Sustainability; Sustainable forest management; Wood consumption

Contact information: a: Bioresource and Biorefinery Laboratory, National University of Malaysia, Selangor, Malaysia; b: Center for Water Cycle, Marine Environment and Disaster Management, Kumamoto University, Kumamoto, Japan; c: Faculty of Economics and Management, National University of Malaysia, Selangor, Malaysia; d: School of Mathematical Sciences, National University of Malaysia, Selangor, Malaysia; e: Malaysian Timber Industry Board (MTIB), Menara PGRM, Wilayah Persekutuan Kuala Lumpur, Malaysia; *Corresponding author: szakaria@ukm.edu.my

\section{INTRODUCTION}

Malaysia's timber industry is classified into two groups of timber sectors known as sawnwood and panel products, the latter of which includes plywood and veneer, particleboard/chipboard, medium density fibreboard (MDF), veneered panel products, mouldings, builders, joinery and carpentry (BJC), and furniture. The timber industry is also is an important source of domestic economic revenue, and it is dominated by small to medium sized companies. Parallel with Malaysia's governance, the launching of the $11^{\text {th }}$ Malaysia Plan 2016-2020 is important to Malaysian timber-based small mediumenterprises (SMEs) in order to continue being the fundamental agenda in transforming Malaysia into a developed nation (SME Corporation Malaysia 2016).

Because timber produces major marketable products, effective forest management is required to maintain the sustainability of this industry (Siry et al. 2005). Forest products in Malaysia have generated significant offerings that are important to the socio-economy (Islam and Siwar 2010; Osman et al. 2014). However, the extraction of timber has the potential to lead to deforestation, which is becoming the main problem for the lessdeveloped and forest industry-practicing countries (Shittu et al. 2019). The Food and Agricultural Organization of the United Nations (FAO) has reported that the world's forest 
area has been reduced to $30.6 \%$ from $31.6 \%$ during the time period 1990 to 2015. Although the deforestation factors are still debatable, agriculture, mining, urbanization, and infrastructure development have been considered to be the drivers of deforestation (Hosonuma et al. 2012). Also, through ecology and biodiversity improvement, the reversal of total land degradation and the Sustainable Forest Management (SFM) have been highlighted in the $15^{\text {th }}$ Sustainable Development Goals (SDGs), where the particular assessments are focusing on improving the sustainably managed forests.

Table 1. Percentage of Forest Area Proportion of the Global Land Area in Year 1990, 2010, and 2015 (FAO 2019)

\begin{tabular}{|c|c|c|c|}
\hline \multirow{2}{*}{ Region } & \multicolumn{3}{|c|}{ Forest Area Proportion of Global Land Area in 25 } \\
\cline { 2 - 4 } & Year 1990 & Year 2010 & Year 2015 \\
\cline { 2 - 4 } & 17.4 & 16.8 & 17.0 \\
\hline Australia and New Zealand & 40.3 & 40.9 & 41.0 \\
\hline Europe and North America & 28.5 & 29.4 & 29.6 \\
\hline Eastern and Southeast Asia & 30.6 & 27.7 & 27.1 \\
\hline Sub-Saharan Africa & 51.3 & 47.0 & 46.4 \\
\hline Latin America and the Caribbean & 9.5 & 10.0 & 10.0 \\
\hline Central and Southern Asia & 3.9 & 3.8 & 3.8 \\
\hline Northern Africa and Western Asia & 70.1 & 70.1 & 70.1 \\
\hline $\begin{array}{c}\text { Oceania (exclude New Zealand and } \\
\text { Australia) }\end{array}$ & & & \\
\hline
\end{tabular}

The forest is considered to be the primary point of man's sustenance supplies. The forest is vital in carbon sequestration. It regulates the global temperature, provides shelter for a variety of living things, and supplies requisite biomass (Espinoza et al. 2012; Anderegg et al. 2013; Siwar et al. 2016; Baker et al. 2019). The 'new forestry' initiatives have delivered the concept of sustainable development since the 1990s by merging resources' utilization and biodiversity conservation into the SFM. In regards to this, the concept of 'new forestry' must be treated as a complex ecosystem and practicing a well managed timber harvest (Gillis 1990). The SFM is based on societal legitimacy, economic viability, and ecological sustainability (Arts and Buizer 2009; Islam et al. 2010; Arts et al. 2013). Restoration of the forests potentially can be achieved through SFM, which is defined as guiding principles to manage the forests. The International Tropical Timber Organization (ITTO) (2005) has defined SFM as:

"The process of managing forest to achieve one or more specified objectives of management concerning the production of a continuous flow of desired forest products and services without undue reduction of its inherent values and future productivity and without undesirable effects on the physical and social environment".

By embracing the definition above, forest-associated activities should not bring any harm to the forest and should provide balance towards ecological, economic, and social concerns (McDonald and Lane 2004; Noraida et al. 2017). SFM brings the concept of sustainability, where, the guidelines aim to meet the current needs and not compromise the future necessities (MacDicken et al. 2015; Sauer and Seuring 2017). It is a tailored approach that provides strong grasp and appeases the various interest in forests of different stakeholders (Rametsteiner and Simula 2003; Fabusoro et al. 2014).

A few agencies and institutions in Peninsular Malaysia are responsible for managing the forests and improving the wood-based industry development apart from state governments such as Ministry of Plantation Industries and Commodities (MPIC), Ministry 
of Natural Resources and Environment, Malaysia Timber Industry Board (MTIB), Malaysia Timber Council (MTC) and Malaysian Timber Certification Council (MTCC). By benefiting the socio-economic development, water, soil and wildlife conservation and environmental protection, Peninsular Malaysia's forest's role is protected and conserved under the regulation of SFM (Jusoff and Taha 2008). The Forestry Department of Malaysia has taken initiatives in implementing Forest Management Certification (FMC) to achieve the sustainably managed forest. Forest certification navigates and ensures that the forest products comply with environmental standards, rules, and regulations. The implementation of SFM has been positively affected by the timber industry, as has been shown in several studies. For example, studies showed the SFM had positively affected the production of logs despite having a reduction in the harvested area (Azian et al. 2017; Noraida et al. 2017). The implementation of SFM has caused the reduction of log supply from Malaysia's natural forests (Halis et al. 2015). Forest usage in the timber industry was controlled by SFM practice, where it showed a positive impact in timber supply in the short run analysis (Suryani et al. 2011).

Two organizations issue the certification of FMC at the international level: Forest Stewardship Council (FSC) and the Program for the Endorsement of Forest Certification (PEFC). Malaysia had taken initiatives to introduce FMC under Malaysian Timber Certification Schemes (MTCS) on natural forest and forest plantations. There are six forest management units in Peninsular Malaysia certified that cover 3.78 million hectares to date (Table 2) (Malaysian Timber Council Certification n.d.). The progress of FMUs is monitored and evaluated based on Malaysian Criteria and Standards obeying the FSC and PEFC principles and criteria (Suryani et al. 2011). They are also conducting forest-related activities to bring of ecological, biological, and socio-cultural sustainability to Peninsular Malaysia (Jusoff and Taha 2008).

Purchase of the sustainably produced timber has been encouraged by many governments, thus creating a well-governed marketization of the wood products (Visserenhamakers 2013). Moreover, improved market access and wood products' quality are gained through sustainably managed forests that are derived from this initiative (Siry et al. 2005). Increasing demand for green labelling of products has been observed, which is termed 'green marketing' through green certification (Vlosky et al. 1999; Aguilar and Cai 2010; Papadopoulos et al. 2010). Kollert and Lagan (2007) showed that certified logs achieved market premium compared to uncertified logs that only reach a lower market premium price. However, the goal of certification programs varies based on the participants' interests that include awareness of customers about sustainably managed forests and environment (Kiker and Putz 1997).

Table 2. List of Forest Management Units in Peninsular Malaysia Region and Size of Certified Area Covered (MTCC 2019)

\begin{tabular}{|c|c|}
\hline Forest Management Unit (FMU) & Size (ha) \\
\hline Kedah State Forestry Department & $334,983.00$ \\
\hline Negeri Sembilan State Forestry Department & $155,649.56$ \\
\hline Pahang State Forestry Department & $1,504,407.35$ \\
\hline Perak State Forestry Department & $998,306.02$ \\
\hline Selangor State Forestry Department & $238,748.83$ \\
\hline Terengganu State Forestry Department & $544,936.58$ \\
\hline Total (ha) & $3,777,031.34$ \\
\hline
\end{tabular}

Armir et al. (2020). "Malaysia wood industries," BioResources 15(2), 2971-2993. 


\section{Theoretical Framework}

The main objective of this study is to investigate the relationship between raw materials' consumption patterns and operation with the sustainability of the Peninsular Malaysia wood-based industry with respect to SFM and non-SFM practitioners. A set of questions had been derived from the possible formulated hypotheses to connect the relationship of raw materials' consumption patterns and operation with the wood industry's sustainability. Initially, it is assumed that the timber mills' owners are practicing SFM as a sustainable wood-based industry because they are certified and regulated by forestry department to manifest the SFM.

The necessity to make the wood-based industry sustainable is vital to achieving a sustainable nation. As an approach to achieving this goal, SFM is being introduced. The sustainability assessment based on the Criteria and Indicator (C \& I) tools to support the concept that is manifested in SFM (Castañeda 2000; Wulf 2003). In this modern society, forests' demand is not only concentrated on a sustained timber supply per se. Rather, many forests' attributes products are in great demand. Peninsular Malaysia has developed an extensive set of C\&Is for SFM known as MC\& I, which practice an economic and efficient harvesting utilization, sustained yield of timber and reforestation, as well as the maintenance of forest development. The Forestry Department of Malaysia is carrying out the pre-felling inventory to rule out uncertainties with respect to the status of the forest. Alongside, silvicultural treatment is employed in the logging area with an applied moratorium for re-harvesting. The operated timber mills in Peninsular must be registered with the Forest Department of Peninsular Malaysia and certified with the PEFC and FSC through the MC\&I by MTCS scheme to support the SFM. The certified timber mills that practiced SFM is regarded as sustainable, as the inspection will be held by the Forest Department authorities following the MC\&Is.

Reduced Impact Logging (RIL) began in Malaysia in August 1992 based on principal goals of soil and residual stand damage reduction upon performing selective logging in the logged area (Pinard et al. 1995; Er et al. 2011). According to Putz et al. (2008), it is defined as "intensively planned and carefully controlled timber harvesting conducted by trained workers in ways that minimize the deleterious impacts of logging." However, the silvicultural goal of timber sustaining yield is barely achieved because high harvesting intensities are still performed. Additionally, RIL is more sensible to be engaged by the large-scale wood-based industry because its principals are converging to the industrial-scale level wood industry operation. Regarding this, the percentage of logs' consumption in manufacturing wood products was considered. The goal was to observe how far does the dependency of Peninsular Malaysia wood-based industry on logs extend as raw materials, in light of the fact that RIL was implemented.

The demand for wood-based products is increasing worldwide, coupled with the increment in population growth (Gemechu et al. 2010). This is enhanced by the characteristics of wood as a renewable resource, possessing low resource input and environmentally friendly products (Martínez-Alonso and Berdasco 2015). According to the Sustainable Development Goals 12, the sustainable consumption and production aims to advocate a better life quality to all communities through efficient resource and energy, sustainable infrastructure, and develop an accessible basic services and better jobs direction. The consumption and production pattern must be sustainable to reduce environmental deterioration and to empower future development. By taking these factors into consideration, three types of questions were designed. Firstly, the questions on the trend of demand and supply of raw materials in 5 and 10 years were asked to evaluate the 
pattern prediction of raw materials' demand and supply by the timber mills owners. Next, their dependency on imported raw materials and sufficiency of raw materials were designed. If they are depending on imported raw materials, it is assumed that they are having scarcity of raw materials or the quality of domestic raw materials is not satisfied by the timber mills owner. In addition, the type of raw materials that are available might be not suited to the desired products. The level of technology was also a part of the questions to identify the level of technology advancement used by the timber mills in manufacturing their products. Referring to this, technologies' employment also offers alternatives to modernize the wood-based industry in some aspects. It potentially lessens the demand pressure for forest products without causing any customers' inconvenience in ways of employment of non-wood based products, increasing in re-use and recycling the materials, and using the computational approach in wood products manufacturing, management, and monitoring (Sayer et al. 1997). More advanced technologies will produce more innovative wood products, reduce the manpower, and increase the efficiency of the production. Considering the SFM and non-SFM practitioner of Peninsular Malaysia wood-based industry, are their raw materials' consumption patterns and operation influencing their sustainability?

\section{METHODOLOGICAL SECTION}

\section{Data}

As a research setting, a census of all Peninsular Malaysia timber mills was used. The census frame considered all the timber mills in Peninsular Malaysia ranging from the northern, southern, central, and eastern coast and covering 11 states of Peninsular Malaysia in the period of February 2018 until December 2018 ( $\mathrm{N}=1447)$. The updated lists of targeted timber mills were drawn from Malaysia Timber Industry Board (MTIB), Forest Department of Peninsular Malaysia (FDPM), and the State Forestry Department in the sectors of furniture, sawmilling, plywood and veneer, particleboard and chipboard, builders, joinery and carpentry (BJC), moulding, and medium density fibreboard (MDF). The census questionnaires were sent to the assigned mills two weeks before the collection date of self-completion forms. The questions were designed to measure the sustainability of the Peninsular Malaysia wood-based industry. Nine questions were asked in the questionnaires related to the potential factors that influence the readiness of the Peninsular Malaysia timber industry with respect to achieving sustainability. The questions were based on the sufficiency of raw materials, the trend of demand and supply of raw materials, level of technology used, the log's consumption percentage for producing wood products, the usage of imported raw materials, and the awareness of SFM.

Respondents were classified into three categories according to their major type of raw materials consumption in manufacturing their wood products. Sawmills and plywood and veneer mills are categorized into primary wood processing industries as they were operating by using roundwood as their raw materials. Sawmills cut the roundwood into sawntimber, while plywood and veneer mills utilized the roundwood and converted them into plywood and veneer by using specialized types of machinery. Next, the secondary wood processing industries consisted of medium density fibreboard (MDF) mills, laminated board mills, wooden pallet mills, moulding mills, particleboard mills, builders, joinery, and carpentry (BJC) mills, where these mills consumed sawntimber or plywood and veneer products and primary wood processing industries' manufacturing waste for their 
wood products' production. The last type of wood process was the tertiary wood processing industry that covered the furniture mills, where they used raw materials from primary and secondary wood processing industries in producing furniture.

\section{Multiple Correspondence Analysis (MCA)}

A multiple correspondence analysis (MCA), a descriptive technique, has been employed in social science research to disclose the relationship between categorical variables and execute the output via graphical technique generated from the transformation of numeric information on a multiple contingency table of the categorical data (Greenacre 2000; Fellenberg et al. 2001; 2000; Panagiotakos and Pitsavos 2004; Sourial et al. 2010). For operating MCA, RStudio software (Boston, MA, USA) was used. MCA uses the concept of homogeneity, which refers to the different variables measuring the same characteristic or characteristics, represented using a joint map. A collective view of the data is simplified and uses the graphical illustration to interpret the relationship between the data. It uses the frequency provided by the Burt table to distribute all variables into computed dimensions. The joint map shows the relative closeness and indiscretion of the individuals and variable categories. It is assumed to have no hypothesized model and underlying distribution. The individuals and variable categories are represented in the form of coordinates that are plotted in the center of gravity of the individual points driven by particular variable categories. The closer the individual points to the particular variable categories indicates the close relationship between them. This technique is used to explore the correspondence between the type of wood processing industry and wood sustainability factors in respect to SFM practitioners and non-SFM practitioners. The validity of MCA is evaluated by several complementary approaches as following:

- Number of dimensions is calculated on the difference between the sum of variables categories and the sum of variables.

- Inertia shows data dispersion around the centroid or gravity or known to be information measure. The calculated inertia is calculated by dividing the maximum number of possible MCA dimensions with the number of variables.

- The squared cosine (cosine $e^{2}$ ) shows the quality of variables and represents the distribution of the inertia of the particular variables across dimensions. The value is lower than 0.1 is regarded as poor presenting to each dimension.

- Eigenvalues are obtained by performing MCA to dictate how many dimension should explain the data. The highest eigenvalue is placed in the first dimension and it will progressively decrease in subsequent dimensions. The eigenvalues with the calculated inertia $>0.2$ is included in the data interpretation.

To conduct MCA, the R-package named 'FactoMineR' and 'factoextra' previously installed in RStudio software (Boston, MA) were used. The biplot was generated to visualize the low dimensional data approximation.

\section{Variables and Variable Categories}

Respondents or the individuals were classified by the following: type of wood processing industries, which comprises primary, secondary, and tertiary types of wood processing industry; their awareness towards sustainable forest management (SFM); sufficiency of raw materials to operate (SUF); usage of imported raw materials (IMP); 
consumption of logs in manufacturing products (LOG); prediction on raw materials' supply in the next 5 years (SUP5) and 10 years (SUP10) and demand in the next 5 years (DEM5) and 10 years (DEM10); and level of technological advancement employed in the business operation (TEC). The type of industry according to raw materials used in wood processing (IND) was regarded as the supplementary categorical variables. The variable categories represent the answers to the questions and are further analyzed using MCA.

\section{RESULTS}

\section{Descriptive Analysis}

Table 3 shows the percentage of response rate regarding the questions given. A positive response rate was obtained for all three respondents' groups. The blank answer in either of the questions was omitted in further analysis. Most of the wood sector practices SFM in operating their business except for the laminated board (LB) and wooden pallet (WDN) sector in the secondary wood processing industry. Moreover, the furniture (FR) sector shows that less mills are practicing SFM. Surprisingly, sawmill (SM) shows a higher percentage of not practicing the SFM. The majority of the wood sector states that they are having sufficient raw materials but only sawmilling (SM) and wooden pallet (WDN) sectors are recorded to have a higher percentage of respondents answering 'insufficient'. Most of them predict that the raw materials supply and demand will be decreasing and increasing for the next 5 and 10 years, respectively. However, the medium density fibreboard (MDF) sector in the second wood processing industry predicts them to be unchanging. The logs or roundwood consumed by all wood processing are recorded to be more than $80 \%$ in producing their wood products operated by semi-automated types of machinery.

Table 3. Percentage of Response Rate for Nine Questions Regarding the Potential Factors Influencing the Sustainability of Peninsular Malaysia Woodbased Industry

\begin{tabular}{|c|c|c|c|}
\hline \multirow{2}{*}{ Question } & \multicolumn{3}{|c|}{ Response Rate (\%) } \\
\cline { 2 - 4 } & \multicolumn{2}{|c|}{ Type of Wood Processing } \\
\cline { 2 - 4 } & Primary & Secondary & Tertiary \\
\hline Sustainable Forest Management awareness (SFM) & $75.89 \%$ & $100 \%$ & $100 \%$ \\
\hline Sufficiency of raw materials (SUF) & $92.71 \%$ & $100 \%$ & $100 \%$ \\
\hline Imported raw materials usage (IMP) & $94.77 \%$ & $100 \%$ & $100 \%$ \\
\hline Logs consumption in manufacturing wood products (LOG) & $82.24 \%$ & $87.41 \%$ & $93.61 \%$ \\
\hline Raw materials' supply in 5 years (SUP5) & $93.08 \%$ & $100 \%$ & $100 \%$ \\
\hline Raw materials' supply in 10 years (SUP10) & $88.60 \%$ & $100 \%$ & $100 \%$ \\
\hline Raw materials' demand in 5 years (DEM5) & $92.52 \%$ & $100 \%$ & $100 \%$ \\
\hline Raw materials' demand in 10 years (DEM10) & $88.41 \%$ & $100 \%$ & $100 \%$ \\
\hline Level of technology employment (TEC) & $95.14 \%$ & $100 \%$ & $100 \%$ \\
\hline
\end{tabular}


Table 4. Descriptive Statistics of the Response for Every Variables for Primary Wood Processing Industries

\begin{tabular}{|c|c|c|c|}
\hline \multicolumn{4}{|c|}{ Primary Wood Processing Industries } \\
\hline \multirow[t]{2}{*}{ Variable } & \multirow{2}{*}{ Variable Category } & \multicolumn{2}{|c|}{$\%$} \\
\hline & & PV & SM \\
\hline \multirow{2}{*}{ SFM } & Yes & 44.44 & 36.86 \\
\hline & No & 55.56 & 63.14 \\
\hline \multirow{2}{*}{ SUF } & Yes & 67.07 & 46.14 \\
\hline & No & 32.93 & 53.86 \\
\hline \multirow{2}{*}{ IMP } & Yes & 14.12 & 0.95 \\
\hline & No & 85.88 & 99.05 \\
\hline \multirow{3}{*}{ SUP5 } & Decreasing & 44.05 & 60.87 \\
\hline & Increasing & 21.43 & 13.04 \\
\hline & Unchanging & 34.52 & 26.09 \\
\hline \multirow{3}{*}{ SUP10 } & Decreasing & 46.25 & 67.26 \\
\hline & Increasing & 22.50 & 9.64 \\
\hline & Unchanging & 31.25 & 23.10 \\
\hline \multirow{3}{*}{ DEM5 } & Decreasing & 16.67 & 31.87 \\
\hline & Increasing & 45.24 & 36.25 \\
\hline & Unchanging & 38.10 & 31.87 \\
\hline \multirow{3}{*}{ DEM10 } & Decreasing & 12.50 & 34.10 \\
\hline & Increasing & 51.25 & 34.61 \\
\hline & Unchanging & 36.25 & 31.30 \\
\hline \multirow{9}{*}{ LOG (\%) } & 30 & 0.00 & 0.54 \\
\hline & 40 & 0.00 & 1.09 \\
\hline & 50 & 1.39 & 2.72 \\
\hline & 60 & 9.72 & 4.62 \\
\hline & 70 & 6.94 & 9.78 \\
\hline & 80 & 6.94 & 16.03 \\
\hline & 90 & 18.06 & 7.88 \\
\hline & Less than 20 & 6.94 & 1.36 \\
\hline & More than 90 & 50.00 & 55.98 \\
\hline \multirow{4}{*}{ TEC } & Fully-automated & 0.00 & 1.65 \\
\hline & Manual & 20.93 & 38.53 \\
\hline & Robotic & 0.00 & 0.24 \\
\hline & Semi-automated & 79.07 & 59.57 \\
\hline
\end{tabular}


Table 5. Descriptive Statistics of the Response for Every Variables for Secondary Wood Processing Industries

\begin{tabular}{|c|c|c|c|c|c|c|c|}
\hline \multicolumn{8}{|c|}{ Secondary Wood Processing Industries } \\
\hline \multirow{2}{*}{ Variable } & \multirow{2}{*}{$\begin{array}{l}\text { Variable } \\
\text { Category }\end{array}$} & \multicolumn{6}{|c|}{$\%$} \\
\hline & & BJC & LB & MDF & MOU & PAR & WDN \\
\hline \multirow{2}{*}{ SFM } & Yes & 70.37 & 35.14 & 50.00 & 68.18 & 14.29 & 33.33 \\
\hline & No & 29.63 & 64.86 & 50.00 & 31.82 & 85.71 & 66.67 \\
\hline \multirow{2}{*}{ SUF } & Yes & 57.41 & 51.35 & 50.00 & 50.00 & 78.57 & 39.78 \\
\hline & No & 42.59 & 48.65 & 50.00 & 50.00 & 21.43 & 60.22 \\
\hline \multirow{2}{*}{ IMP } & Yes & 12.96 & 48.65 & 0 & 19.70 & 21.43 & 7.53 \\
\hline & No & 87.04 & 51.35 & 100.00 & 80.30 & 78.57 & 92.47 \\
\hline \multirow{3}{*}{ SUP5 } & Decreasing & 68.52 & 43.24 & 66.67 & 57.58 & 35.71 & 66.67 \\
\hline & Increasing & 7.41 & 27.03 & 0 & 16.67 & 42.86 & 12.90 \\
\hline & Unchanging & 24.07 & 29.73 & 33.33 & 25.76 & 21.43 & 20.43 \\
\hline \multirow{3}{*}{ SUP10 } & Decreasing & 74.07 & 48.65 & 50.00 & 65.15 & 42.86 & 69.89 \\
\hline & Increasing & 3.70 & 21.62 & 16.67 & 15.15 & 42.86 & 10.75 \\
\hline & Unchanging & 22.22 & 29.73 & 33.33 & 19.70 & 14.29 & 19.35 \\
\hline \multirow{3}{*}{ DEM5 } & Decreasing & 35.19 & 27.03 & 16.67 & 30.30 & 14.29 & 18.28 \\
\hline & Increasing & 22.22 & 37.84 & 50.00 & 42.42 & 71.43 & 55.91 \\
\hline & Unchanging & 42.59 & 35.14 & 33.33 & 27.27 & 14.29 & 25.81 \\
\hline \multirow{3}{*}{ DEM10 } & Decreasing & 48.15 & 32.43 & 16.67 & 37.88 & 21.43 & 22.58 \\
\hline & Increasing & 20.37 & 32.43 & 50.00 & 36.36 & 71.43 & 51.61 \\
\hline & Unchanging & 31.48 & 35.14 & 33.33 & 25.76 & 7.14 & 25.81 \\
\hline \multirow{9}{*}{ LOG (\%) } & 30 & 1.85 & 2.70 & 0 & 0 & 0 & 1.08 \\
\hline & 40 & 1.85 & 0 & 16.67 & 1.52 & 7.14 & 1.08 \\
\hline & 50 & 7.41 & 0 & 0.00 & 4.55 & 0 & 3.23 \\
\hline & 60 & 5.56 & 8.11 & 0.00 & 3.03 & 0 & 3.23 \\
\hline & 70 & 5.56 & 13.51 & 0 & 9.09 & 14.29 & 3.23 \\
\hline & 80 & 3.70 & 10.81 & 0 & 12.12 & 14.29 & 8.60 \\
\hline & 90 & 16.67 & 8.11 & 16.67 & 12.12 & 21.43 & 12.90 \\
\hline & Less than 20 & 9.26 & 2.70 & 0 & 1.52 & 7.14 & 2.15 \\
\hline & More than 90 & 42.59 & 37.84 & 33.33 & 48.48 & 35.71 & 45.16 \\
\hline \multirow{4}{*}{ TEC } & Fully-automated & 0 & 10.81 & 16.67 & 1.52 & 7.14 & 2.15 \\
\hline & Manual & 29.63 & 16.22 & 16.67 & 30.30 & 21.43 & 36.56 \\
\hline & Robotic & 3.70 & 2.70 & 0 & 0 & 0 & 0 \\
\hline & Semi-automated & 66.67 & 70.27 & 66.67 & 68.18 & 71.43 & 61.29 \\
\hline
\end{tabular}


Table 6. Descriptive Statistics of the Response for Every Variables for Tertiary Wood Processing Industries

\begin{tabular}{|c|c|c|}
\hline \multicolumn{3}{|c|}{ Tertiary Wood Processing Industries } \\
\hline \multirow{2}{*}{ Variable } & \multirow{2}{*}{ Variable Category } & $\%$ \\
\hline & & FR \\
\hline \multirow{2}{*}{ SFM } & Yes & 30.69 \\
\hline & No & 69.31 \\
\hline \multirow{2}{*}{ SUF } & Yes & 71.18 \\
\hline & No & 28.82 \\
\hline \multirow{2}{*}{ IMP } & Yes & 20.25 \\
\hline & No & 79.75 \\
\hline \multirow{3}{*}{ SUP5 } & Decreasing & 44.39 \\
\hline & Increasing & 26.01 \\
\hline & Unchanging & 29.60 \\
\hline \multirow{3}{*}{ SUP10 } & Decreasing & 46.11 \\
\hline & Increasing & 26.32 \\
\hline & Unchanging & 27.57 \\
\hline \multirow{3}{*}{ DEM5 } & Decreasing & 24.45 \\
\hline & Increasing & 43.77 \\
\hline & Unchanging & 31.78 \\
\hline \multirow{3}{*}{ DEM10 } & Decreasing & 25.86 \\
\hline & Increasing & 42.99 \\
\hline & Unchanging & 31.15 \\
\hline \multirow{9}{*}{ LOG (\%) } & 30 & 3.89 \\
\hline & 40 & 4.67 \\
\hline & 50 & 5.45 \\
\hline & 60 & 8.41 \\
\hline & 70 & 6.54 \\
\hline & 80 & 15.89 \\
\hline & 90 & 18.07 \\
\hline & Less than 20 & 6.07 \\
\hline & More than 90 & 24.61 \\
\hline \multirow{4}{*}{ TEC } & Fully-automated & 2.96 \\
\hline & Manual & 28.35 \\
\hline & Robotic & 1.25 \\
\hline & Semi-automated & 67.45 \\
\hline
\end{tabular}

\section{Multiple Correspondence Analysis}

\section{MCA dimensions}

Categories points that are close to the mean are plotted near the centroid and vice versa. The similar distribution of the categories are located near each other in the map or are joined together as a group. The maximum number of possible MCA dimensions is calculated to be 22 (difference between sum of variable categories (31) and variables (9)). 
The calculated inertia is 2.44 (maximum number of possible dimensions (22) divides by sum of variables (9)). A higher eigenvalue indicates a larger total variance among the variables on the particular dimension. The eigenvalue is shown to be greater at the two top dimensions, which quantifies $26.07 \%$ variances of all dimensions (out of 22 dimensions) with the highest percentage of variance being 14\% (Fig. 1). A constant decrease of eigenvalues is seen throughout other dimensions. These top 2 dimensions are retained as the joint map or biplot. The commensurate low eigenvalues in the recorded dimensions imply that the variables used in this data are heterogeneous and the removal of any of the variables could affect the output information.

Table 7. Eigenvalue and Percentage Variance for each Dimension for MCA Result of 10 out of 22 Dimensions

\begin{tabular}{|c|c|c|}
\hline Dimension & Eigenvalue & Percentage Variance (\%) \\
\hline 1 & 0.3418689 & 13.985545 \\
\hline 2 & 0.2954876 & 12.088130 \\
\hline 3 & 0.1723984 & 7.752662 \\
\hline 4 & 0.1342759 & 5.493104 \\
\hline 5 & 0.1258922 & 5.150136 \\
\hline 6 & 0.1220078 & 4.991229 \\
\hline 7 & 0.1182096 & 4.835848 \\
\hline 8 & 0.1128354 & 4.615992 \\
\hline 9 & 0.1113807 & 4.556485 \\
\hline 10 & 0.1111768 & 4.548141 \\
\hline
\end{tabular}

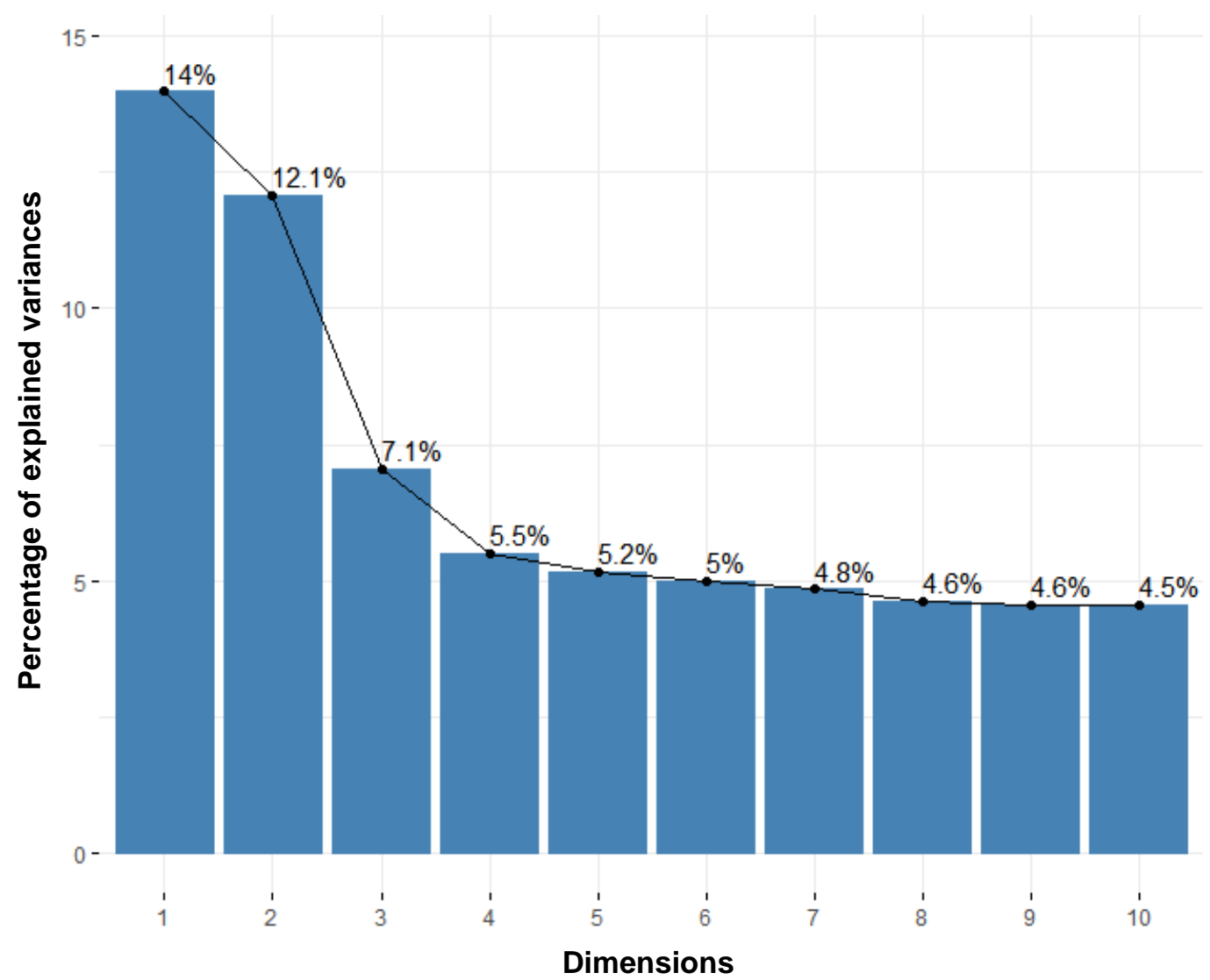

Fig. 1. Visualization plot of percentage of variance in 10 dimensions (out of 22 dimensions) 
The visualization of information is the key benefit of using MCA. The visualized data are presented in the form of a biplot or joint map, which elaborately shows the relative closeness between the individuals and variables and between variables and variable categories. Variable contribution depends on the number of categories of the particular variable, while the category contribution is data-dependent. A biplot has been constructed to show the relative closeness of variables categories (Fig. 2). All types of processing industries are shown to be concentrated along dimension 2 . The primary type of processing industries are shown to have associated with manual types of machinery employment in producing the plywood, veneer, and sawntimber. As for secondary type wood processing industries, semi-automated technologies are likely to be used, as they show a close relationship between each other. Both of these industries use local raw materials in sustaining their production. Secondary type wood processing industries were also observed to form close relationships with unawareness of SFM and high log percentage consumption. This is because some of the facilities in the primary wood processing industry are also producing some secondary wood products that makes a timber mill possess two types of wood processing industry, which are primary and secondary. Next, as for the tertiary type wood processing industry, where it is mainly focused on the furniture industry, the individuals' points form a close association with $20 \%$ and $60 \% \operatorname{logs}$ consumption, sufficient raw materials, and awareness of SFM.

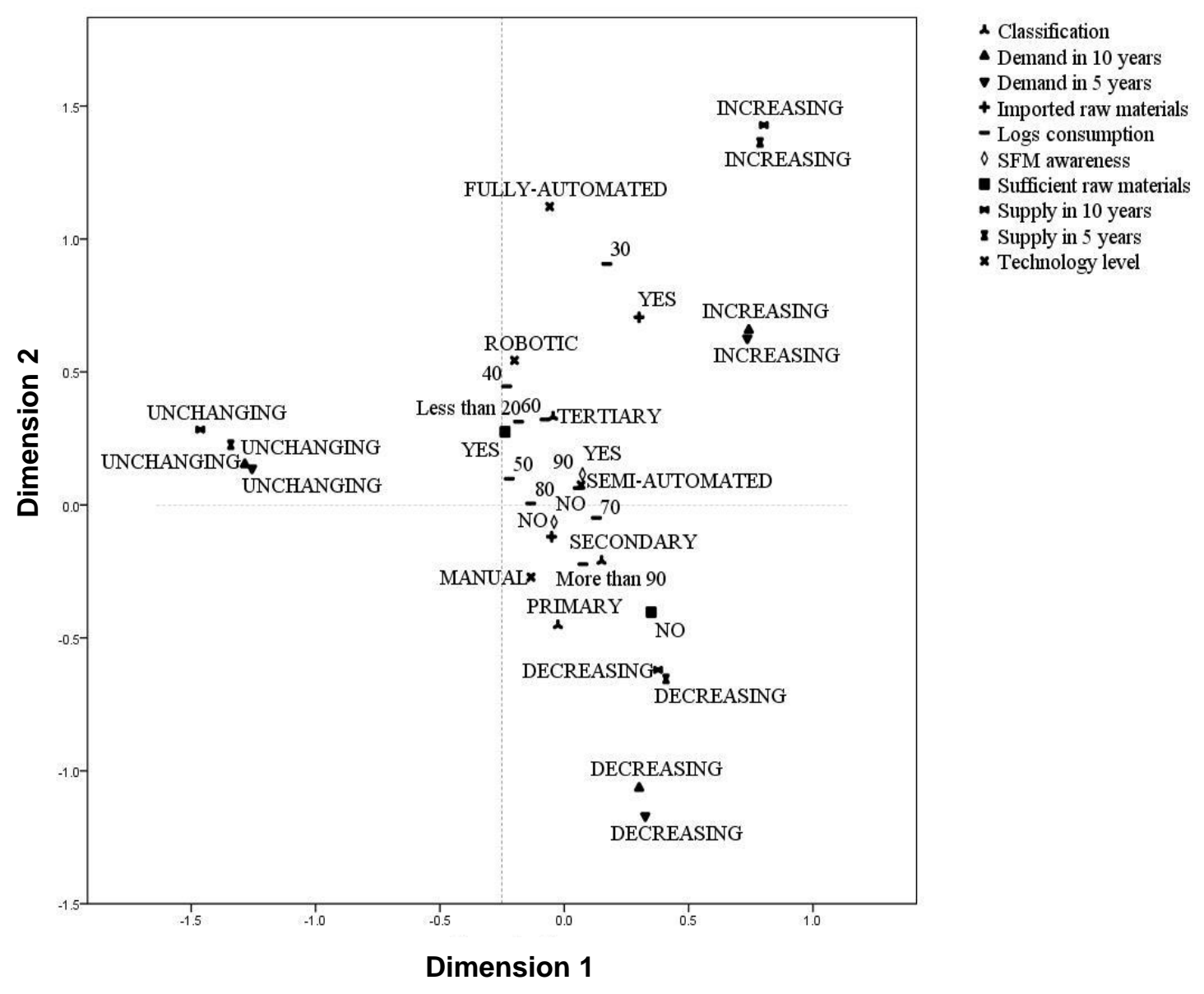

Fig. 2. Biplot of individuals and variables categories 
The habillage and ellipses functions are utilized in further analysis of individuals that are aware and unaware of SFM (Fig. 3). This is employed to group the non-SFM and SFM awareness group to further observe their behavior in practicing sustainable wood industry business.

The implementation of SFM in the Peninsular Malaysia wood-based industry is not extending any awareness to business owners in creating a sustainable wood industry future. This is due to the lack of any obvious pattern of variables categories' points observed as the group of SFM and non-SFM awareness as they lie on the same groups (presented by the loop shapes).

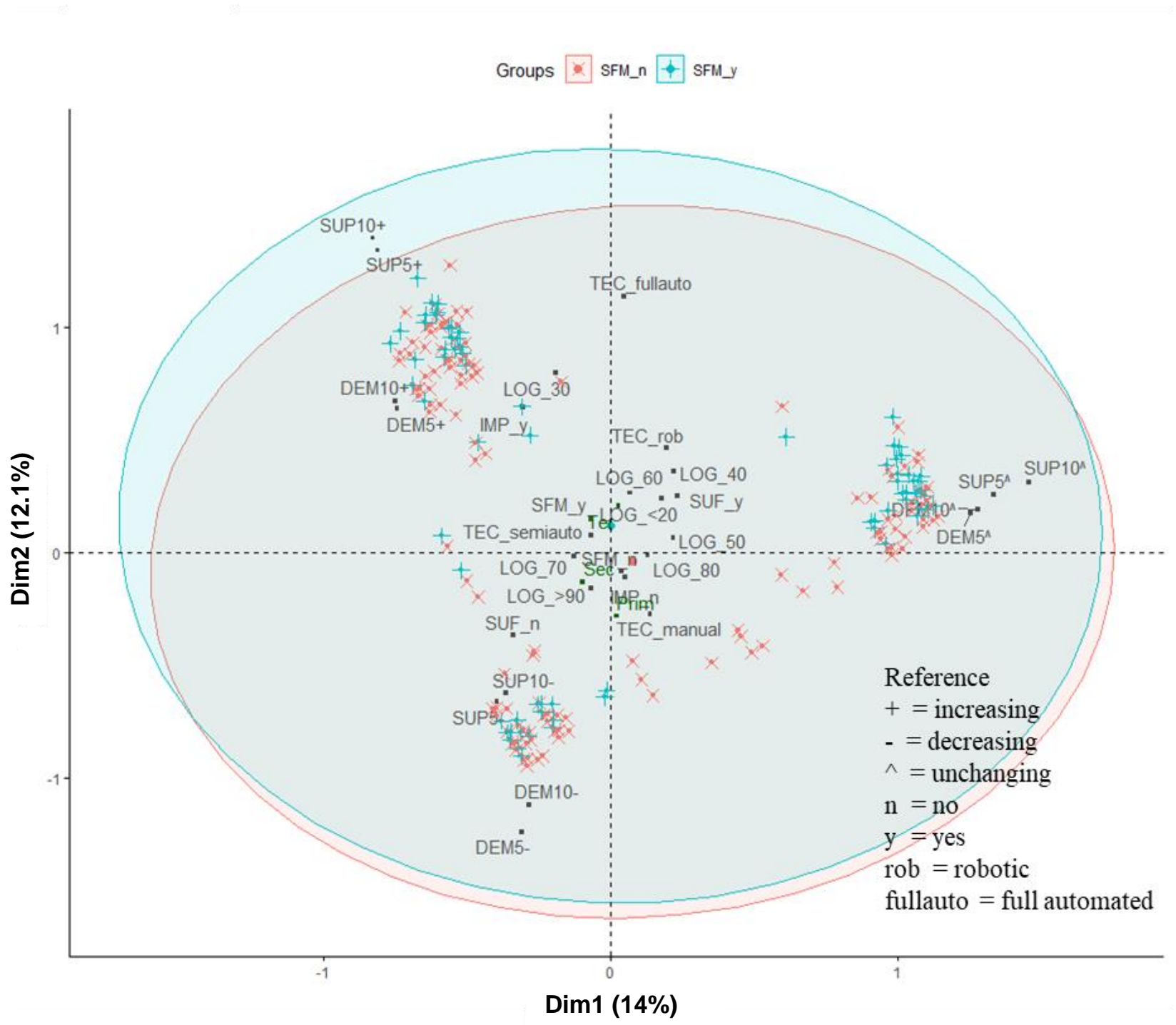

Fig. 3. Biplot of individuals and variables categories that classifies into SFM_y (aware of SFM) and SFM_n (unaware of SFM). The groups are displayed by inserting the ellipses around the individuals and variables categories coordinates by. Only the individuals possess $\cos ^{2}>0.2$ and 30 highest contribution of variables categories in both dimensions are drawn in the biplot. 


\section{DISCUSSION}

MCA was employed to find the interdependencies relationship between the potential sustainability factors towards sustainability. It should be noted that the abiding sustainability of the Peninsular Malaysia timber industry cannot be solely dependent on the current presented result. Besides, further consecutive investigations must be done to derive the readiness of the Peninsular Malaysia wood industry towards sustainability.

The implementation of Forest Management Certification is endorsed by PEFC via the MTCS in Peninsular Malaysia on the evaluation basis tailoring to the Malaysia Standards Criteria and Indicators for Forest Management Certification (Natural Forests). The certifying bodies, known as Forest Management Unit (FMU), are subjected to be the important tier-one supply chain of the Peninsular Malaysia timber industry as they follow the law and regulations in supplying the logs to the timber mills according to the principles of SFM. However, Peninsular Malaysia is still lacking of FMUs, which could have resulted from the lack of support from government in term of incentives, loans, and assistance, as well as higher fees applied for the certification process. Some of the business owners might encounter some difficulties understanding the whole complex process of getting certified, More key actors of the Peninsular Malaysia timber industry must achieve certification by the Forest Management Certification scheme, as it will bring the positive synergies in attaining the SFM towards a sustainable timber industry in Peninsular Malaysia.

The sustainable timber industry is largely determined by its raw materials sourcing. Raw materials are mostly obtained from the planted forests; thus, sustainably managed forests are important in ensuring the preservation of natural forests' conversion into fastgrowing planted forests (FAO 2009). SFM regulation in Peninsular Malaysia has brought the restriction of logging activities in Peninsular Malaysia (Shigematsu et al. 2011; Sills et al. 2018). Timber harvesting is often related to deforestation, where its impact is considered to be 'unsustainable'. The extraction of timber from the assigned harvested area must be replanted and regrown; however, if the trees are harvested during agricultural expansion or the harvested areas are not replaced, it will result in deforestation (Damette and Delacote 2011).

The findings of this study show that the cognizance of SFM in the Peninsular Malaysia timber industry is potentially not holistically reaching each of the forestry business owners. The respondents for this association are not aware of the SFM regulation despite the initiatives and programs that had been carried out by the government. The great reliance on wood as the raw materials have shown that the Peninsular Malaysia timber industry still requires continuous wood supply from the forest abroad or locally despite the confined timber harvesting activities. Constant reliance on a huge amount of wood as the major raw materials in producing timber products will keep the Peninsular Malaysia timber industry struggling to reach a sustainable business. The growing population also causes the needs of forests' transformation to fit the urbanization with simultaneously increase in wood demand for human needs, economic development, and bioenergy. The huge consumption of logs in constructing timber products in Peninsular Malaysia might be significantly drawn from the scarce innovation. Also, huge dependency on logs as the raw materials in sustaining the timber-based business will give negative impacts on the environment. Regarding this, there are the release of greenhouse gases due to transporting the raw materials from forest to end users. Several other gas components such as carbon dioxide, ammonium, nitrous oxide, sulphur dioxide, and carbon monoxide are being discharged upon utilizing logs (Adhikari and Ozarska 2018). Thus, business owners obtain 
the imported logs supply, where, this strategy affects the time and cost-wise practice. Also, the Peninsular Malaysia timber industry is lacking competent employees with good skills in timber market exposure and knowledge in handling advanced techniques and machinery (Ratnasingam et al. 2013).

Awareness and knowledge about "getting certified" in the Malaysia timber industry are said to be relatively slow (Ratnasingam et al. 2013). This could be driven by SMEs culture that has largely determined the Peninsular Malaysia timber industry, where they are afraid to get certified and having the mindset that the certification process is complicated. This issue needs to be solved, as SMEs function to sustain the global and regional economies (Ayyagari et al. 2007) They are considered as business carriers to promote new innovation for the industry and life sustaining-motivated that are vital in the value chain with dynamic intervention (Chirisa et al. 2012; Li et al. 2014).

Timber certification benefits the business in various ways, notably in product branding, customers' trust acquisition, and extensive product marketing that will increase the industry's revenue. Running as the most important timber sector, and carrying a branding of environmentally friendly products is much preferred by the customers and buyers.

\section{CONCLUSIONS}

Forests are renewable resources that benefit humans in terms of economic growth, job opportunities, and urbanization. However, a sustainably managed forest is vital to sustaining their role for future generations. A census study was carried out to find the relationship between the raw materials' consumption pattern and operation with the sustainability of Peninsular Malaysia wood-based industry.

1. It was found that the idea of sustainably managed forests is not completely grasped by the Peninsular Malaysia wood industry, and more efforts are necessary to deliver the importance of sustainability practice in administering their wood-based business. Small-sized wood companies that dominate the Peninsular Malaysia wood industry must be able to be more proactive and open-minded in exposing their business to SFM policies and criteria.

2. With the scarcity of raw materials due to restriction of logging implementation in Malaysia, operating the sustainable managed wood-based business will provide a more efficient way of manufacturing wood products and waste management.

3. Results of this study suggest that a huge amount of wood is consumed by small-sized wood mills, and these mills are not aware of SFM regulation despite experiencing raw materials shortages. This result has important implications for responsible authorities to monitor and guide the Peninsular Malaysia wood industry towards sustainability. Further research is necessary to evaluate the status of the Peninsular Malaysia wood industry towards sustainability, where the wood products' production data from each companies and the size of the companies should be collected to discuss their behavior towards sustainable wood industry based on the respective classification. 


\section{ACKNOWLEDGMENTS}

The authors thank the members of State Forestry Department, Forestry Department of Peninsular Malaysia, Malaysia Timber Industry Board, and enumerators for logistical support and valuable assistance. This project is funded by Malaysia Timber Industry Board and research grant scheme from Malaysia Ministry of Higher Education FRGS/1/2018/ STG07/UKM/01/1.

\section{REFERENCES CITED}

Adhikari, S., and Ozarska, B. (2018). "Minimizing environmental impacts of timber products through the production process 'From Sawmill to Final Products,", Environmental Systems Research 7(6), 1-15. DOI: 10.1186/s40068-018-0109-x

Anderegg, W. R. L., Kane, J. M., and Anderegg, L. D. L. (2013). "Consequences of widespread tree mortality triggered by drought and temperature stress," Nature Climate Change 3(January), 30-36. DOI: 10.1038/NCLIMATE1635

Arts, B., Behagel, J. H., van Bommel, S., de Koning, J., and Turnhout, E. (2013). Forest and Nature Governance: A Practice Based Approach, Springer, Dordrecht. DOI: 10.1007/978-94-007-5113-2

Arts, B., and Buizer, M. (2009). "Forests, discourses, institutions: A discursiveinstitutional analysis of global forest governance," Forest Policy and Economics 11(5-6), 340-347. DOI: 10.1016/j.forpol.2008.10.004

Ayyagari, M., Beck, T., and Demirguc-Kunt, A. (2007). "Small and medium enterprises across the globe," Small Business Economics 29(4), 415-434. DOI: 10.1007/s11187006-9002-5

Azian, M., Ismail, P., Abd Rahman, K., Samsudin, M., Mohd Nizam, M. S., Nur Hajar, Z. S., Azmer, M., Lim, K. L., and Yusoff, M. (2017). "Comparative study of carbon emission changes from different logging techniques in inland production forest in Pahang," Malaysian Forester 80(1), 111-124.

Baker, J. S., Wade, C. M., Sohngen, B. L., Ohrel, S., and Fawcett, A. A. (2019). "Potential complementarity between forest carbon sequestration incentives and biomass energy expansion," Energy Policy 126, 391-401. DOI:

10.1016/j.enpol.2018.10.009

Castañeda, F. (2000). "Criteria and indicators for sustainable forest management: International processes, current status and the way ahead," Unasylva 51(203), 24-40.

Chirisa, I., Dumba, S., and Mukura, T. (2012). "Innovative, adaptive and survivalist strategies by small business enterprises in Zimbabwe (1990 - 2009 ): Implications for policy and planning," International Journal of Academic Research in Business and Social Sciences 2(5), 114-132.

Damette, O., and Delacote, P. (2011). "Unsustainable timber harvesting, deforestation and the role of certification," Ecological Economics 70(6), 1211-1219. DOI: 10.1016/j.ecolecon.2011.01.025

Er, A. C., Abidin, R. D. Z. R. Z., and Pereira, J. J. (2011). "Sustainable development of Lagong Hill forest reserve, Malaysia," Australian Journal of Basic and Applied Sciences 5(7), 364-370.

Espinoza, O., Buehlmann, U., and Smith, B. (2012). "Forest certification and green building standards: Overview and use in the U.S. hardwood industry," Journal of 
Cleaner Production 33, 30-41. DOI: 10.1016/j.jclepro.2012.05.004

Fabusoro, E., Maruyama, M., Shoyama, K., and Braimoh, A. K. (2014). "Community institutions, sustainable forest management, and forest cover change in southern Japan," Journal of Sustainable Forestry 33(1), 1-20. DOI:

10.1080/10549811.2013.803189

Fellenberg, K., Hauser, N. C., Brors, B., Neutzner, A., Hoheisel, J. D., and Vingron, M. (2001). "Correspondence analysis applied to microarray data," Proceedings of the National Academy of Sciences 98(19), 10781-10786. DOI: 10.1073/pnas.181597298

Gemechu, E., Butnar, I., Goma-Camps, J., Pons, A., and Castells, F. (2010). Life Cycle Assessment and Forest Products: A White Paper, Forest Products Association of Canada, Ottawa, Canada.

Gillis, A. M. (1990). "The new forestry: An ecosystem approach to land management," BioScience 40(8), 558-562.

Greenacre, M. (2000). "Correspondence analysis of square asymmetric matrices," Journal of the Royal Statistical Society. Series C: Applied Statistics 49(3), 297-310. DOI: 10.1111/1467-9876.00193

Halis, R., Bakar, E. S., Ramasamy, G., Muttiah, N., and Ratnasingam, J. (2015). "Assessment of environmental emissions from sawmilling activity in Malaysia," BioResources 10(4), 6643-6662. DOI: 10.15376/biores.10.4.6643-6662

Hosonuma, N., Herold, M., Sy, V. De, Fries, R. S. De, Brockhaus, M., Verchot, L., Angelsen, A., and Romijn, E. (2012). "An assessment of deforestation and forest degradation drivers in developing countries," Environment Research Letters 7(4). DOI: $10.1088 / 1748-9326 / 7 / 4 / 044009$

Islam, R., and Siwar, C. (2010). "Trade and environment in the forestry sector: Towards sustainable forest management," Asian Journal of Scientific Research 3(1), 1-17.DOI: 10.3923/ajsr.2010.1.17

Islam, R., Siwar, C., Mohamad Ismail, S., and Chamhuri, N. H. (2010). "Criteria and indicators for sustainable forest management in Malaysia," American Journal of Environmental Sciences 6(3), 212-218. DOI: 10.3844/ajessp.2010.212.218

Jusoff, K., and Taha, D. H. D. H. (2008). "Sustainable forest management practices and environmental protection in Malaysia," WSEAS Transactions on Environment and Development 4(3), 191-199.

Kiker, C. F., and Putz, F. E. (1997). "Ecolocical certification of forest products: Economic challenges," Ecological Economics 20(1), 37-51. DOI: 10.1016/S09218009(96)00076-6

Kollert, W., and Lagan, P. (2007). "Do certified tropical logs fetch a market premium?. A comparative price analysis from Sabah, Malaysia," Forest Policy and Economics 9(7), 862-868. DOI: 10.1016/j.forpol.2006.03.005

Li, N., Toppinen, A., and Lantta, M. (2014). "Managerial perceptions of SMEs in the wood industry supply chain on corporate responsibility and competitive advantage: Evidence from China and Finland," Journal of Small Business Management 2014, 125. DOI: $10.1111 / \mathrm{jsbm} .12136$

MacDicken, K. G., Sola, P., Hall, J. E., Sabogal, C., Tadoum, M., and de Wasseige, C. (2015). "Global progress toward sustainable forest management," Forest Ecology and Management 352, 47-56. DOI: 10.1016/j.foreco.2015.02.005

Malaysian Timber Council Certification. (n.d.). "Certified Forest Management Unit (FMU)," Malaysian Timber Council Certification, Accessed (https://mtcc.com.my/certified-forests/) Aug. 22, 2019. 
Martínez-Alonso, C., and Berdasco, L. (2015). "Carbon footprint of sawn timber products of Castanea sativa Mill. in the north of Spain," Journal of Cleaner Production 102(June), 127-135. DOI: 10.1016/j.jclepro.2015.05.004

McDonald, G. T., and Lane, M. B. (2004). "Converging global indicators for sustainable forest management," Forest Policy and Economics 6(1), 63-70. DOI: 10.1016/S13899341(02)00101-6

Noraida, A. W., Abdul Rahim, A. S., and Mohd-Shahwahid, H. O. (2017). "The impact of sustainable forest management (SFM) practices on primary timber-based production in peninsular Malaysia (Kesan Amalan pengurusan hutan secara Mampan (SFM) kepada pengeluaran produk berasaskan kayu di semenanjung Malaysia)," Jurnal Ekonomi Malaysia 51(2), 159-172.

Osman, N. B., Othman, H. T., Karim, R. A., Amir, M., and Mazlan, F. (2014). "Biomass in Malaysia: Forestry-based residues," International Journal of Biomass \& Renewables 3(1), 7-14.

Panagiotakos, D. B., and Pitsavos, C. (2004). "Interpretation of epidemiological data using multiple correspondence analysis and log-linear models," Journal of Data Science 2, 75-86.

Papadopoulos, I., Karagouni, G., Trigkas, M., and Platogianni, E. (2010). “Green marketing the case of greece in certified and sustainably managed timber products," EuroMed Journal of Business, 5(2), 166-190. DOI: 10.1108/14502191011065491

Pinard, M. A., Putz, F. E., Tay, J., and Sullivan, T. E. (1995). "Creating timber harvest guidelines for a reduced-impact logging project in Malaysia," Journal of Forestry 93(10), 41-45. DOI: 10.1093/jof/93.10.41

Putz, F. E., Sist, P., Fredericksen, T., and Dykstra, D. (2008). "Reduced-impact logging: Challenges and opportunities," Forest Ecology and Management 256(7), 1427-1433. DOI: 10.1016/j.foreco.2008.03.036

Rametsteiner, E., and Simula, M. (2003). "Forest certification - An instrument to promote sustainable forest management?," Journal of Environmental Management, 67(1), 8798. DOI: 10.1016/S0301-4797(02)00191-3

Ratnasingam, J., Wai, L. T., Thanasegaran, G., Ioras, F., Vacalie, C., Coman, C., and Wenming, L. (2013). "Innovations in the forest products industry: The Malaysian experience," Not Bot Horti Agrobo 41(2), 601-607.

Sauer, P. C., and Seuring, S. (2017). "Sustainable supply chain management for minerals," Journal of Cleaner Production 151, 235-249. DOI: 10.1016/j.jclepro.2017.03.049

Sayer, J. A., Vanclay, J. K., and Byron, N. (1997). "Technologies for sustainable forest management: Challenges for the $21^{\text {st }}$ century," Commonwealth Forestry Review 76(3), 162-170.

Schweinle, J. (2007). "Wood \& Other Renewable Resources: A challenge for LCA wooden building products in comparative LCA: A literature review," International Journal of LCA 12(3), 141-142. DOI: 10.1065/lca2007.04.326

Shigematsu, A., Mizoue, N., Kajisa, T., and Yoshida, S. (2011). "Importance of rubberwood in wood export of Malaysia and Thailand," New Forests 41(2), 179-189. DOI: $10.1007 / \mathrm{s} 11056-010-9219-7$

Shittu, W. O., Musibau, H., and Hassan, S. (2019). "Revisiting the environmental Kuznets curve in Malaysia: The interactive roles of deforestation and urbanisation," International Journal of Green Economics 12(3/4), 272-293. DOI: 10.1504/IJGE.2018.097872 
Siry, J. P., Cubbage, F. W., and Ahmed, M. R. (2005). "Sustainable forest management: Global trends and opportunities," Forest Policy and Economics 7(4), 551-561. DOI: 10.1016/j.forpol.2003.09.003

Siwar, C., Chinade, A. A., Ismail, S. M., and Isahak, A. (2016). "Economic valuation of soil carbon sequestration services in Malaysia's forest sector: A review of possible approaches," Journal of Sustainability Science and Management 11(1), 14-28.

SME Corporation Malaysia. (2016). SME Annual Report 2015-2016, SME Corporation Malaysia. DOI: 10.5860/crln.77.11.9594

Sourial, N., Wolfson, C., Zhu, B., Quail, J., Fletcher, J., Karunananthan, S., BandeenRoche, K., Béland, F., and Bergman, H. (2010). "Correspondence analysis is a useful tool to uncover the relationships among categorical variables," Journal of Clinical Epidemiology 63(6), 638-646. DOI: 10.1016/j.jclinepi.2009.08.008

Suryani, A. G. N., Shahwahid, H. O. M., Fauzi, P. A., Alias, R., and Vlosky, R. P. (2011). "Assessment of chain-of-custody certification costs for sawnwood manufacturers in peninsular Malaysia," Journal of Tropical Forest Science 23(2), 159-165. DOI: https://www.jstor.org/stable/23616916

Visseren-hamakers, I. J., and Pattberg, P. (2013). "We can't see the forest for the trees," GAIA - Ecological Perspectives for Science and Society 22(1), 25-28. DOI: 10.14512/gaia.22.1.8

Vlosky, R. P., Ozanne, L. K., and Fontenot, R. J. (1999). "A conceptual model of US consumer willingness-to-pay for environmentally certified wood products," Journal of Consumer Marketing 16(2), 122-140. DOI: 10.1108/07363769910260498

Wulf, M. (2003). "Forest policy in the EU and its influence on the plant diversity of woodlands," Journal of Environmental Management 67(1), 15-25. DOI: 10.1016/S0301-4797(02)00184-6

Article submitted: November 11, 2019; Peer review completed: January 23, 2020; Revised version received: March 4, 2020; Accepted: March 7, 2020; Published: March 13, 2020.

DOI: 10.15376/biores.15.2.2971-2993 


\section{APPENDIX}

Table S1. Descriptive Statistics of the Response for Every Variables for Primary Wood Processing Industries

\begin{tabular}{|c|c|c|c|}
\hline \multicolumn{4}{|c|}{ Primary Wood Processing Industries } \\
\hline \multirow[t]{2}{*}{ Variable } & \multirow[t]{2}{*}{ Variable Category } & \multicolumn{2}{|c|}{$\%$} \\
\hline & & PV & SM \\
\hline \multirow[t]{2}{*}{ SFM } & Yes & 44.44 & 36.86 \\
\hline & No & 55.56 & 63.14 \\
\hline \multirow[t]{2}{*}{ SUF } & Yes & 67.07 & 46.14 \\
\hline & No & 32.93 & 53.86 \\
\hline \multirow[t]{2}{*}{ IMP } & Yes & 14.12 & 0.95 \\
\hline & No & 85.88 & 99.05 \\
\hline \multirow[t]{3}{*}{ SUP5 } & Decreasing & 44.05 & 60.87 \\
\hline & Increasing & 21.43 & 13.04 \\
\hline & Unchanging & 34.52 & 26.09 \\
\hline \multirow[t]{3}{*}{ SUP10 } & Decreasing & 46.25 & 67.26 \\
\hline & Increasing & 22.50 & 9.64 \\
\hline & Unchanging & 31.25 & 23.10 \\
\hline \multirow[t]{3}{*}{ DEM5 } & Decreasing & 16.67 & 31.87 \\
\hline & Increasing & 45.24 & 36.25 \\
\hline & Unchanging & 38.10 & 31.87 \\
\hline \multirow[t]{3}{*}{ DEM10 } & Decreasing & 12.50 & 34.10 \\
\hline & Increasing & 51.25 & 34.61 \\
\hline & Unchanging & 36.25 & 31.30 \\
\hline \multirow[t]{9}{*}{ LOG (\%) } & 30 & 0.00 & 0.54 \\
\hline & 40 & 0.00 & 1.09 \\
\hline & 50 & 1.39 & 2.72 \\
\hline & 60 & 9.72 & 4.62 \\
\hline & 70 & 6.94 & 9.78 \\
\hline & 80 & 6.94 & 16.03 \\
\hline & 90 & 18.06 & 7.88 \\
\hline & Less than 20 & 6.94 & 1.36 \\
\hline & More than 90 & 50.00 & 55.98 \\
\hline \multirow[t]{4}{*}{ TEC } & Fully-automated & 0.00 & 1.65 \\
\hline & Manual & 20.93 & 38.53 \\
\hline & Robotic & 0.00 & 0.24 \\
\hline & Semi-automated & 79.07 & 59.57 \\
\hline
\end{tabular}


Table S2. Descriptive Statistics of the Response for Every Variables for Secondary Wood Processing Industries

\begin{tabular}{|c|c|c|c|c|c|c|c|}
\hline \multicolumn{8}{|c|}{ Secondary Wood Processing Industries } \\
\hline \multirow{2}{*}{ Variable } & \multirow{2}{*}{ Variable Category } & \multicolumn{6}{|c|}{$\%$} \\
\hline & & BJC & LB & MDF & MOU & PAR & WDN \\
\hline \multirow[t]{2}{*}{ SFM } & Yes & 70.37 & 35.14 & 50.00 & 68.18 & 14.29 & 33.33 \\
\hline & No & 29.63 & 64.86 & 50.00 & 31.82 & 85.71 & 66.67 \\
\hline \multirow[t]{2}{*}{ SUF } & Yes & 57.41 & 51.35 & 50.00 & 50.00 & 78.57 & 39.78 \\
\hline & No & 42.59 & 48.65 & 50.00 & 50.00 & 21.43 & 60.22 \\
\hline \multirow[t]{2}{*}{ IMP } & Yes & 12.96 & 48.65 & 0 & 19.70 & 21.43 & 7.53 \\
\hline & No & 87.04 & 51.35 & 100.00 & 80.30 & 78.57 & 92.47 \\
\hline \multirow[t]{3}{*}{ SUP5 } & Decreasing & 68.52 & 43.24 & 66.67 & 57.58 & 35.71 & 66.67 \\
\hline & Increasing & 7.41 & 27.03 & 0 & 16.67 & 42.86 & 12.90 \\
\hline & Unchanging & 24.07 & 29.73 & 33.33 & 25.76 & 21.43 & 20.43 \\
\hline \multirow[t]{3}{*}{ SUP10 } & Decreasing & 74.07 & 48.65 & 50.00 & 65.15 & 42.86 & 69.89 \\
\hline & Increasing & 3.70 & 21.62 & 16.67 & 15.15 & 42.86 & 10.75 \\
\hline & Unchanging & 22.22 & 29.73 & 33.33 & 19.70 & 14.29 & 19.35 \\
\hline \multirow[t]{3}{*}{ DEM5 } & Decreasing & 35.19 & 27.03 & 16.67 & 30.30 & 14.29 & 18.28 \\
\hline & Increasing & 22.22 & 37.84 & 50.00 & 42.42 & 71.43 & 55.91 \\
\hline & Unchanging & 42.59 & 35.14 & 33.33 & 27.27 & 14.29 & 25.81 \\
\hline \multirow[t]{3}{*}{ DEM10 } & Decreasing & 48.15 & 32.43 & 16.67 & 37.88 & 21.43 & 22.58 \\
\hline & Increasing & 20.37 & 32.43 & 50.00 & 36.36 & 71.43 & 51.61 \\
\hline & Unchanging & 31.48 & 35.14 & 33.33 & 25.76 & 7.14 & 25.81 \\
\hline \multirow[t]{9}{*}{ LOG (\%) } & 30 & 1.85 & 2.70 & 0 & 0 & 0 & 1.08 \\
\hline & 40 & 1.85 & 0 & 16.67 & 1.52 & 7.14 & 1.08 \\
\hline & 50 & 7.41 & 0 & 0.00 & 4.55 & 0 & 3.23 \\
\hline & 60 & 5.56 & 8.11 & 0.00 & 3.03 & 0 & 3.23 \\
\hline & 70 & 5.56 & 13.51 & 0 & 9.09 & 14.29 & 3.23 \\
\hline & 80 & 3.70 & 10.81 & 0 & 12.12 & 14.29 & 8.60 \\
\hline & 90 & 16.67 & 8.11 & 16.67 & 12.12 & 21.43 & 12.90 \\
\hline & Less than 20 & 9.26 & 2.70 & 0 & 1.52 & 7.14 & 2.15 \\
\hline & More than 90 & 42.59 & 37.84 & 33.33 & 48.48 & 35.71 & 45.16 \\
\hline \multirow[t]{4}{*}{ TEC } & Fully-automated & 0 & 10.81 & 16.67 & 1.52 & 7.14 & 2.15 \\
\hline & Manual & 29.63 & 16.22 & 16.67 & 30.30 & 21.43 & 36.56 \\
\hline & Robotic & 3.70 & 2.70 & 0 & 0 & 0 & 0 \\
\hline & Semi-automated & 66.67 & 70.27 & 66.67 & 68.18 & 71.43 & 61.29 \\
\hline
\end{tabular}


Table S3. Descriptive Statistics of the Response for Every Variables for Tertiary Wood Processing Industries

\begin{tabular}{|c|c|c|}
\hline \multicolumn{3}{|c|}{ Tertiary Wood Processing Industries } \\
\hline \multirow[b]{2}{*}{ Variable } & \multirow{2}{*}{ Variable Category } & $\%$ \\
\hline & & FR \\
\hline \multirow[t]{2}{*}{ SFM } & Yes & 30.69 \\
\hline & No & 69.31 \\
\hline \multirow[t]{2}{*}{ SUF } & Yes & 71.18 \\
\hline & No & 28.82 \\
\hline \multirow[t]{2}{*}{ IMP } & Yes & 20.25 \\
\hline & No & 79.75 \\
\hline \multirow[t]{3}{*}{ SUP5 } & Decreasing & 44.39 \\
\hline & Increasing & 26.01 \\
\hline & Unchanging & 29.60 \\
\hline \multirow[t]{3}{*}{ SUP10 } & Decreasing & 46.11 \\
\hline & Increasing & 26.32 \\
\hline & Unchanging & 27.57 \\
\hline \multirow[t]{3}{*}{ DEM5 } & Decreasing & 24.45 \\
\hline & Increasing & 43.77 \\
\hline & Unchanging & 31.78 \\
\hline \multirow[t]{3}{*}{ DEM10 } & Decreasing & 25.86 \\
\hline & Increasing & 42.99 \\
\hline & Unchanging & 31.15 \\
\hline \multirow[t]{9}{*}{ LOG (\%) } & 30 & 3.89 \\
\hline & 40 & 4.67 \\
\hline & 50 & 5.45 \\
\hline & 60 & 8.41 \\
\hline & 70 & 6.54 \\
\hline & 80 & 15.89 \\
\hline & 90 & 18.07 \\
\hline & Less than 20 & 6.07 \\
\hline & More than 90 & 24.61 \\
\hline \multirow[t]{4}{*}{ TEC } & Fully-automated & 2.96 \\
\hline & Manual & 28.35 \\
\hline & Robotic & 1.25 \\
\hline & Semi-automated & 67.45 \\
\hline eference: FR & & \\
\hline
\end{tabular}




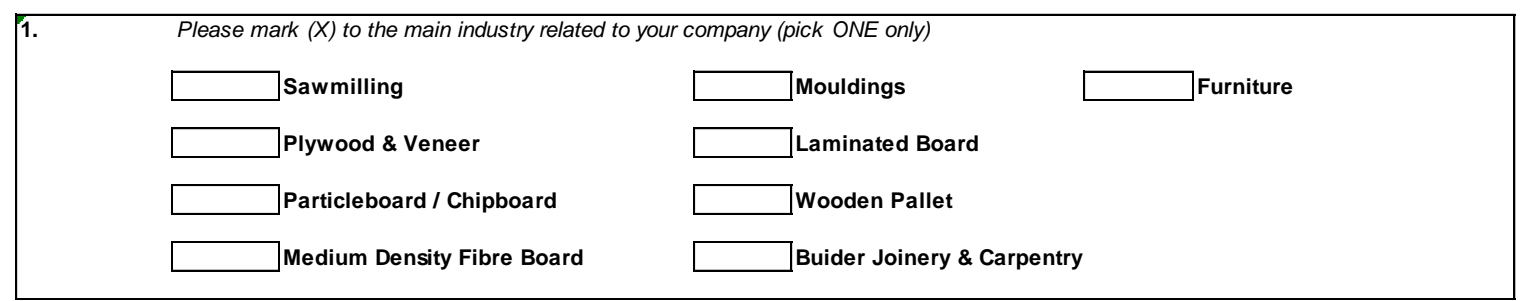

2. Does your company use any raw materials imported from abroad?

$\square$ Yes

\begin{tabular}{|c|c|c|c|}
\hline \multirow[t]{4}{*}{3.} & What is the percen & e amount & uced by your company? \\
\hline & ]$<20 \%$ & $40-50 \%$ & $70-80 \%$ \\
\hline & ] $20-30 \%$ & $50-60 \%$ & $80-90 \%$ \\
\hline & $30-40 \%$ & $60-70 \%$ & $>90 \%$ \\
\hline
\end{tabular}

\begin{tabular}{|c|c|c|}
\hline 4. & How do you forecast about supply & \\
\hline & 4.1. $\ln 5 y$ & 4.2. $\ln 10$ \\
\hline & Increasing & Increasing \\
\hline Supply & Decreasing & Decreasing \\
\hline & Unchanging & Unchanging \\
\hline
\end{tabular}

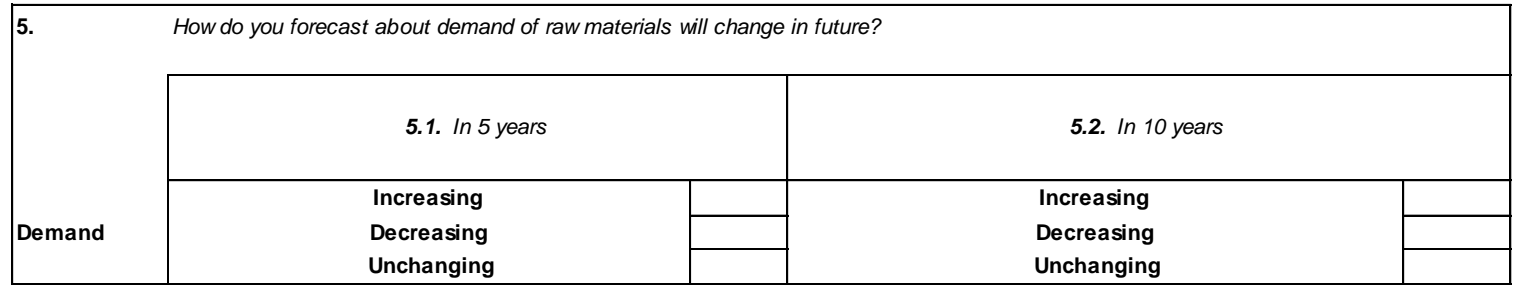

6. Is the supply of the raw materials adequate for your industry

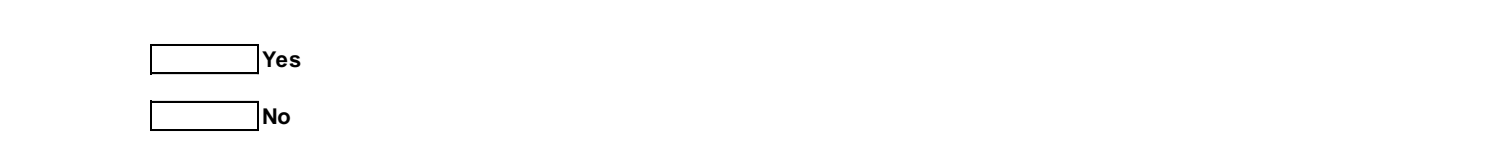

7. $\quad$ Are you aware of Sustainable Forest Management (SFM) certificates?
$\begin{array}{r}\square \text { Yes } \\ \quad \text { No }\end{array}$

What type of technology does your company use in the production process?
\[ \text { Robotic } \]
$\square$ Sully automatic
$\square$ Semi automatic
$\square$ Manual

\section{Questionnaires.}

